$\xi=1$ 国

\title{
Net income prediction of several leading bank in Indonesia using neural approach
}

\author{
Rofiqoh $^{1,1 a}$, Achmad Fanany Onnilita Gaffar ${ }^{2 *}$, Djoko Setyadi ${ }^{3}$, Syarifah Hudayah $^{3}$ \\ ${ }^{1}$ Student Doctoral Management, Faculty of Economics and Business, Mulawarman University, East Kalimantan, Indonesia \\ ${ }^{1 a}$ Department of Accounting, State Polytechnic of Samarinda, East Kalimantan, Indonesia \\ ${ }^{2}$ Department of Information Technology, State Polytechnic of Samarinda, East Kalimantan, Indonesia \\ ${ }^{3}$ Faculty of Economics and Business, Mulawarman University, East Kalimantan, Indonesia \\ *Corresponding author E-mail: onnygaffar212@gmail.com
}

\begin{abstract}
The IFRS (International Financial Reporting Standards) defines net income as synonymous with profit and loss. Net income can be used as a consideration for investment decision making for investors who will invest their capital into a company. Net income for the next year cannot be ascertained but can be predicted by using several financial ratios that affect the change in net income. This study tries to predict net income next year by using several financial ratios obtained from four leading banks in Indonesia. The time series data modeling by using Artificial Neural Network (ANN) based Auto-Regressive with Exogenous input (ARX) model. In this study only use one net structure to model time series data in order to improve the efficiency of the model. Back-Propagation (BP) doing backpropagation to fix the weight of each layer of ANN such that to achieve appointed target error.
\end{abstract}

Keywords: net income, financial ratios, ANN-based ARX model

\section{Introduction}

Assessing a company's stock is a difficult task. The task is simplified by drawing data from the financial statements generated by the company and calculating various financial ratios by using those data. This ratio helps the analysts about whether the company has enough liquidity to pay bills that will mature in the short term, and how effectively the company collects money from its customers. Information from financial statements can be used to assess the overall performance of a company. Ratio analysis is not just a calculation of the given ratio. More important is how to interpret the value of the ratio. A meaningful basis for comparison is needed to answer questions like "Is it too high or too low?", "Is that good or bad?" Two types of comparison comparisons can be made, cross-sectional and time series. The cross-sectional analysis involves comparison of different corporate finance ratios at the same time point. Time series analysis evaluates performance over time. Company progress can be assessed by comparing the current performance with past performance. Financial ratios can be divided for convenience into five basic categories: liquidity, activity, debt, profitability, and market ratios. Liquidity, activity, and debt ratio are mainly used to measure risk, profitability ratios are used to measure returns, while market ratios capture both risk and return. The net income is an entity's income minus the cost of goods sold, expenses and taxes for an accounting period. It has also been defined as the net increase in shareholders' equity results from a company's operations. In the context of financial statements, the IFRS defines net income as synonymous with profit and loss [1]. The company's performance from the management side expects high returns. If company's profits are higher than the company is more flexible in carrying out its operational activities. Net income can be used as a consideration for investment decision making for investors who will invest their capital into a company. Net income for the next year cannot be ascertained but can be predicted by using several financial ratios that affect the change in net income. Prediction is the process of forecasting a variable in the future based on consideration of data in the past and usually represented in time series data. The prediction does not have to give a definite answer to the event that will occur but trying to find the answer as closely as possible that will happen.

There are many methods in doing forecasting activities; outline consists of two approaches that are commonly used statistics and machine learning.

There has been much research on forecasting that has been done by applying various statistical methods. Time series data models such as AR, ARMA, ARX, ARMAX, etc. are also used to model time series data [2-12].

Machine Learning methods have also been used to improve forecasting results. Much research on this has been done, either applying methods independently or combining them with statistical methods [13-22].

This study tries to predict the net income for next year by using several financial ratios obtained from four leading banks in Indonesia based on time series data modeling by using ARX model. Artificial Neural Network Back Propagation (ANN-BP) is used as an approximation model of those ARX model.

There are three types of bank financial ratios. Liquidity ratio is a ratio used to determine the liquidity of a bank to serve its customer. Solvency ratio is a ratio used to measure the bank's effectiveness in achieving its objectives. Profitability ratio is a ratio used to measure the bank's use of its assets and control of its expenses to generate an acceptable rate of return. In this study, several solvency and profitability ratios are used as independent variables, whereas net income as the dependent variable.

The aim of this study is to measure the ANN-BP performance as an approximation model of the ARX model when used in net income prediction activity simultaneously. 


\section{Materials and Methods}

\subsection{Financial Ratios}

In this study using two types of bank financial ratios are solvency and profitability ratios. For solvency ratio chosen DAR and DER, while the profitability ratio is selected ROA and ROE. DAR (Debt to Assets Ratio) is defined as:

$$
\text { DAR }=\frac{\text { Total Liabilities }}{\text { Total Assets }} \times 100 \%
$$

High DAR indicates the low ability to borrow a bank, which in turn will reduce the bank's financial flexibility. In this case, can be stated DAR has a negative influence on changes in net income. DER (Debt to Equity Ratio) is defined as:

$$
\text { DER }=\frac{\text { Total Liabilities }}{\text { Total Equity }} \times 100 \%
$$

Higher DER indicates high total debt of a bank to its total equity. In this case, can be stated DER has a negative influence on changes in net income.

ROA (Return on Assets) is defined as:

$$
R O A=\frac{\text { Net Income }}{\text { Total Assets }} \times 100 \%
$$

Higher ROA indicates the high capital intensity of a bank to its total equity. In this case, can be stated ROA has a positive influence on changes in net income.

ROE (Return on Equity) is defined as:

$$
R O E=\frac{\text { Net Income }}{\text { Total Equity }} \times 100 \%
$$

Higher ROE indicates the higher efficiency level of capital management of a bank. In this case, can be stated ROE has a positive influence on changes in net income.

\subsection{ARX model}

The general structure of ARX model expressed by:

$$
\begin{aligned}
& y(t)+a_{1} y(t-1)+\ldots+a_{n} y(t-n)= \\
& b_{1} x(t-1)+\ldots+b_{m} x(t-m)+e(t)
\end{aligned}
$$

The variables $y(t-1) \ldots y(t-n)$ are the previous outputs whereas $n$ is the number of the previous outputs. The variables ${ }_{x}(t-1) \ldots x(t-m)$ are the previous inputs whereas $m$ is the number of the previous inputs. The variable $e(t)$ is a white noise. The equation (1) can be decomposed into the following [23]:

$$
\begin{aligned}
y(t)= & -a_{1} y(t-1)-\ldots-a_{n} y(t-n) \\
& +b_{1} x(t-1)+\ldots+b_{m} x(t-m)+e(t) \\
& -\left(a_{1} q^{-1}+\ldots+a_{n} q^{-n}\right) y(t) \\
& +\left(b_{1} q^{-1}+\ldots+b_{m} q^{-m}\right) x(t)+e(t) \\
= & -A\left(q^{-1}\right) y(t)+B\left(q^{-1}\right) x(t)+e(t)
\end{aligned}
$$

In Eq. (6), $q^{-1}$ is the delay operator. The forms of $A\left(q^{-1}\right)$ and $B\left(q^{-1}\right)$ are polynomials to be estimated. For MISO-ARX model can be expressed as:

$$
\begin{aligned}
y(t)= & -A\left(q^{-1}\right) y(t)+B_{1}\left(q^{-1}\right) x_{1}(t) \\
& +\ldots+B_{p}\left(q^{-1}\right) x_{p}(t)+e(t)
\end{aligned}
$$

In Eq. (7), $p$ is the number of the input system.

\subsection{ANN-based MISO-ARX model}

The MISO-ARX model in Eq. (7) can be approximated by using Feed Forward Neural Network (FFNN) and expressed by:

$$
\begin{aligned}
& y(t)=N_{f f}\left(\begin{array}{l}
A\left(q^{-1}\right) y(t), \\
B_{1}\left(q^{-1}\right) x_{1}(t), \ldots, B_{p}\left(q^{-1}\right) x_{p}(t)
\end{array}\right)+e(t) \\
& e(t)=y(t)-N_{f f}\left(\begin{array}{l}
A\left(q^{-1}\right) y(t), \\
B_{1}\left(q^{-1}\right) x_{1}(t), \ldots, B_{p}\left(q^{-1}\right) x_{p}(t)
\end{array}\right)
\end{aligned}
$$

By training $N_{f f}(\cdot)$ such that $e(t) \rightarrow 0$ then $N_{f f}(\bullet) \rightarrow y(t)$. In its implementation, $e(t)$ is set as small as possible.

The FFNN architecture used is shown in Figure 1. ANN-BP doing backpropagation to fix the weight of each layer such that to achieve appointed target error [23], as shown in Figure 2.

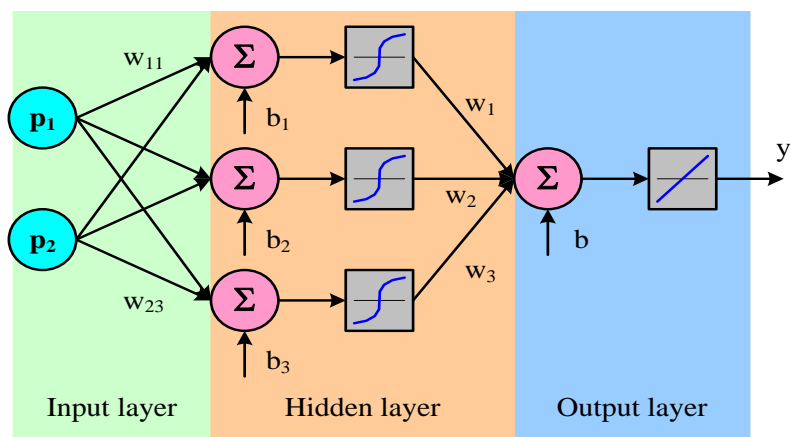

Fig. 1: FFNN architecture

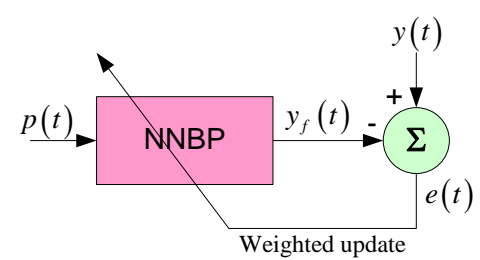

Fig. 2: ANN-BP

The net structure as shown in Figure 1 uses 20 hidden neurons whereas target error $e(t)=10^{-4}$. The performance functions of training results using MSE (Mean Squared Error) which is declared as:

$$
M S E=\frac{1}{N} \sum_{i=1}^{N}\left(y\left(t_{i}\right)-y_{f f}\left(t_{i}\right)\right)^{2}
$$

In Eq. (9), $N$ is the number of the training data, $y(t)$ is the $i$ th training target, and $y_{f f}\left(t_{i}\right)$ is the $i$ th output of ANN-BP. The performance function of trained net structure validation using APE (Absolute Percentage Error) expressed by: 


$$
A P E=\left(1-\frac{\mid \text { actual }- \text { prediction } \mid}{\text { actual }}\right) \times 100 \%
$$

It usually takes one net structure for a set of data obtained from the same data source to describe a good data model. So for four banks, it takes four net structures. In this study only uses one net structure to model the data of all the banks in question. Since there are four banks, therefore, amount of training data is $4 \times 7=28$. Prior to use in the training process, training data needs to be sorted by training target in ascending order to ensure consistency of time series data. The algorithm used in this study is shown in Figure 3 Implementation of ANN-BP is done by using MATLAB programming tool.

\subsection{The proposed method implementation}

The selected banks are BRI, MANDIRI, BCA, and BNI which are classified as leading banks in Indonesia. Data obtained from Indonesia Stock Exchange IDX LQ45 2008 - 2016 [24-28] in the form of total asset, total liability, equity, and net income. DAR, DER, ROA, and ROE are calculated by using Eq. (1) - (4).

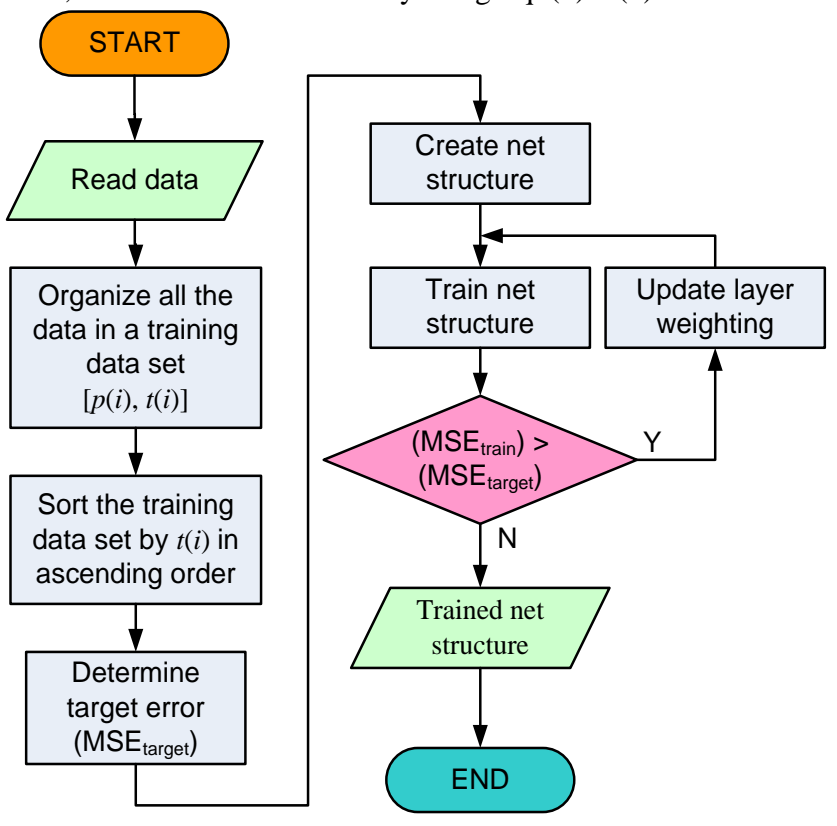

Fig. 3: The algorithm of the proposed method

In this study, the first order MISO-ARX model used is:

$$
\begin{aligned}
y(t)= & -y(t-1)+x_{1}(t-1)+x_{2}(t-1) \\
& +x_{3}(t-1)+x_{4}(t-1)+e(t)
\end{aligned}
$$

The variables are:

$y(t) \quad$ : Net income in a current year.

The data for this variable are from years 2008 - 2014 and used as training input data.

$$
\begin{array}{ll}
y(t-1) & : \text { Net income in a previous year. } \\
x_{1}(t-1) & : \text { DAR in a previous year. } \\
x_{2}(t-1) & : \text { DER in a previous year. } \\
x_{3}(t-1) & : \text { ROA in a previous year. } \\
x_{4}(t-1) & \text { : ROE in a previous year. }
\end{array}
$$

The data for these variables are from years 2009 -2015 and used as a training target. The financial data of selected leading bank in Indonesia are shown in Table $1-8$.
Table 1: Financial Data of BRI Bank as training input data

\begin{tabular}{|c|r|r|r|c|c|}
\hline \multirow{2}{*}{ Year } & \multicolumn{1}{|c|}{$y(t-1)$} & \multicolumn{1}{|c|}{$x_{1}(t-1)$} & \multicolumn{1}{c|}{$x_{2}(t-1)$} & $x_{3}(t-1)$ & $x_{4}(t-1)$ \\
\cline { 2 - 6 } & Net Income & DAR & DER & ROA & ROE \\
\hline 2008 & $5,958,368$ & 0.9091 & 10.0069 & 2.4213 & 26.6514 \\
\hline 2009 & $7,308,292$ & 0.9140 & 10.6279 & 2.3058 & 26.8122 \\
\hline 2010 & $11,472,385$ & 0.9093 & 10.0240 & .8377 & 31.2828 \\
\hline 2011 & $15,087,996$ & 0.8940 & 8.4319 & 3.2109 & 30.2848 \\
\hline 2012 & $18,687,380$ & 0.8823 & 7.4976 & 3.3895 & 28.8022 \\
\hline 2013 & $21,354,330$ & 0.8733 & 6.8937 & 3.4102 & 26.9192 \\
\hline 2014 & $24,253,845$ & 0.8781 & 7.2052 & 3.0243 & 24.8153 \\
\hline
\end{tabular}

Table 2: Financial Data of BRI Bank as training target

\begin{tabular}{|l|r|}
\hline \multirow{2}{*}{ Year } & \multicolumn{2}{|c|}{$y(t)$} \\
\cline { 2 - 3 } & Net Income(+) \\
\hline 2009 & $7,308,292$ \\
\hline 2010 & $11,472,385$ \\
\hline 2011 & $15,087,996$ \\
\hline 2012 & $18,687,380$ \\
\hline 2014 & $21,354,330$ \\
\hline 2015 & $24,253,845$ \\
\hline
\end{tabular}

Table 3: Financial Data of MANDIRI Bank as training input data

\begin{tabular}{|c|r|r|r|r|l|}
\hline \multirow{2}{*}{ Year } & \multicolumn{1}{|c|}{$y(t-1)$} & $x_{1}(t-1)$ & \multicolumn{1}{c|}{$x_{2}(t-1)$} & $x_{3}(t-1)$ & $x_{4}(t-1)$ \\
\cline { 2 - 6 } & Net Income & DAR & DER & ROA & ROE \\
\hline 2008 & $5,312,821$ & 0.9148 & 10.7458 & 1.4822 & 17.4112 \\
\hline 2009 & $7,198,488$ & 0.9106 & 10.2344 & 1.8242 & 20.5034 \\
\hline 2010 & $9,369,226$ & 0.9065 & 9.8141 & 2.0831 & 22.5532 \\
\hline 2011 & $12,695,885$ & 0.8865 & 7.8085 & 2.3004 & 20.2634 \\
\hline 2012 & $16,043,618$ & 0.8796 & 7.3052 & 2.5241 & 20.9630 \\
\hline 2013 & $18,829,934$ & 0.8789 & 7.2565 & 2.5685 & 21.2071 \\
\hline 2014 & $20,654,783$ & 0.8774 & 7.1553 & 2.4157 & 19.7004 \\
\hline
\end{tabular}

Table 4: Financial Data of MANDIRI Bank as training target

\begin{tabular}{|c|r|}
\hline \multirow{2}{*}{ Year } & $y(t)$ \\
\cline { 2 - 3 } & Net Income(+) \\
\hline 2009 & \multicolumn{2}{|c|}{} \\
\hline 2010 & $9,198,488$ \\
\hline 2011 & $12,695,226$ \\
\hline 2012 & $16,043,618$ \\
\hline 2013 & $18,829,934$ \\
\hline 2014 & $20,654,783$ \\
\hline 2015 & $21,152,398$ \\
\hline
\end{tabular}

Table 5: Financial Data of BCA Bank as training input data

\begin{tabular}{|c|r|r|c|c|c|}
\hline \multirow{2}{*}{ Year } & \multicolumn{1}{|c|}{$y(t-1)$} & $x_{1}(t-1)$ & $x_{2}(t-1)$ & $x_{3}(t-1)$ & $x_{4}(t-1)$ \\
\cline { 2 - 6 } & Net Income & DAR & DER & ROA & ROE \\
\hline 2008 & $5,776,139$ & 0.9052 & 9.5488 & 2.3521 & 24.8123 \\
\hline 2009 & $6,807,242$ & 0.9014 & 9.1373 & 2.4106 & 24.4366 \\
\hline 2010 & $8,479,273$ & 0.8949 & 8.5116 & 2.6137 & 24.8602 \\
\hline 2011 & $10,817,798$ & 0.8900 & 8.0871 & 2.8326 & 25.7399 \\
\hline 2012 & $11,718,460$ & 0.8805 & 7.5160 & 2.6453 & 22.5798 \\
\hline 2013 & $14,256,239$ & 0.8711 & 6.7588 & 2.8725 & 22.2870 \\
\hline 2014 & $16,511,670$ & 0.8554 & 6.0645 & 2.9889 & 21.1904 \\
\hline
\end{tabular}

Table 6: Financial Data of BCA Bank as training target

\begin{tabular}{|c|r|}
\hline \multirow{2}{*}{ Year } & \multicolumn{2}{|c|}{$y(t)$} \\
\cline { 2 - 3 } & \multicolumn{2}{|c|}{ Net Income $(+)$} \\
\hline 2009 & \multicolumn{2}{|c|}{} \\
\hline 2010 & $8,479,242$ \\
\hline 2011 & $10,817,798$ \\
\hline 2012 & $11,718,460$ \\
\hline 2013 & $14,256,239$ \\
\hline 2014 & $16,511,670$ \\
\hline 2015 & $18,035,768$ \\
\hline
\end{tabular}


Table 7: Financial Data of BNI Bank as training input data

\begin{tabular}{|c|r|r|r|r|r|}
\hline \multirow{2}{*}{ Year } & \multicolumn{1}{|c|}{$y(t-1)$} & $x_{1}(t-1)$ & $x_{2}(t-1)$ & \multicolumn{1}{c|}{$x_{3}(t-1)$} & \multicolumn{1}{c|}{$x_{4}(t-1)$} \\
\cline { 2 - 6 } & Net Income & DAR & DER & ROA & ROE \\
\hline 2008 & $1,222,485$ & 0.9234 & 12.0716 & 0.6060 & 7.9222 \\
\hline 2009 & $2,486,719$ & 0.9157 & 10.8821 & 1.0931 & 12.9898 \\
\hline 2010 & $4,103,198$ & 0.8666 & 6.5046 & 1.6507 & 12.3890 \\
\hline 2011 & $5,808,218$ & 0.8735 & 6.9026 & 1.9422 & 15.3482 \\
\hline 2012 & $7,048,362$ & 0.8694 & 6.6577 & 2.1147 & 16.1937 \\
\hline 2013 & $9,057,941$ & 0.8767 & 7.1088 & 2.3426 & 18.9960 \\
\hline 2014 & $10,829,379$ & 0.8189 & 5.5906 & 2.5996 & 17.7469 \\
\hline
\end{tabular}

Table 8: Financial Data of BNI Bank as training target

\begin{tabular}{|c|c|}
\hline \multirow{2}{*}{ Year } & \multirow{2}{*}{$\begin{array}{c}y(t) \\
\text { Net Income }(+)\end{array}$} \\
\hline & \\
\hline 2009 & $2,486,719$ \\
\hline 2010 & $4,103,198$ \\
\hline 2011 & $5,808,218$ \\
\hline 2012 & $7,048,362$ \\
\hline 2013 & $9,057,941$ \\
\hline 2014 & $10,829,379$ \\
\hline 2015 & $9,140,532$ \\
\hline
\end{tabular}

Using FFNN can be declared as:

$$
\begin{aligned}
& y(t)=N_{f f}\left(\begin{array}{l}
y(t-1), x_{1}(t-1), \\
x_{2}(t-1), x_{3}(t-1), x_{4}(t-1)
\end{array}\right) \\
& y(i)=N_{f f}(p(i))
\end{aligned}
$$

The ANN-BP training model is shown in Figure 4.

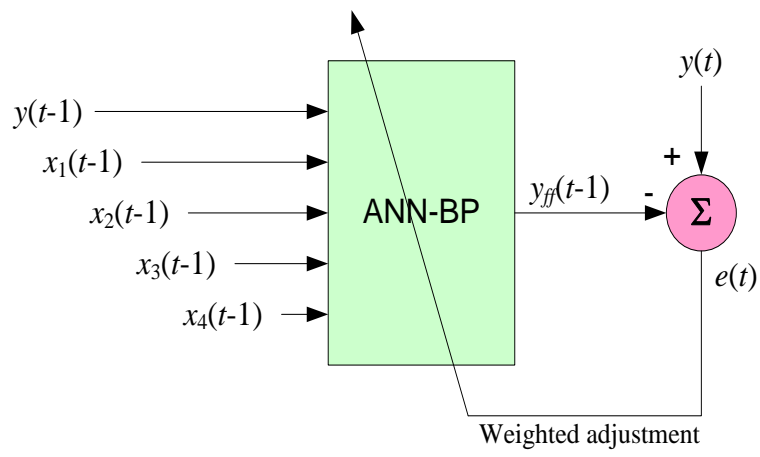

Fig. 4: ANN-BP training model used

The variable $p(i)$ is used as the training input data, and $y(t)=y(i)$ as the training target.

Since all data is used on only one net structure, the pair of training data patterns becomes as follows:

$$
\begin{aligned}
& p(i)=\left[\begin{array}{lllll}
p_{\text {BRI }}(i) & p_{\text {MANDIRI }}(i) & p_{B C A}(i) & p_{B N I}(i)
\end{array}\right] \\
& y(i)=\left[\begin{array}{llll}
y_{\text {BRI }}(i) & y_{\text {MANDIRI }}(i) & y_{B C A}(i) & y_{B N I}(i)
\end{array}\right]
\end{aligned}
$$

\section{Results and discussions}

After the training process is done then the results obtained shown in Figure 5.

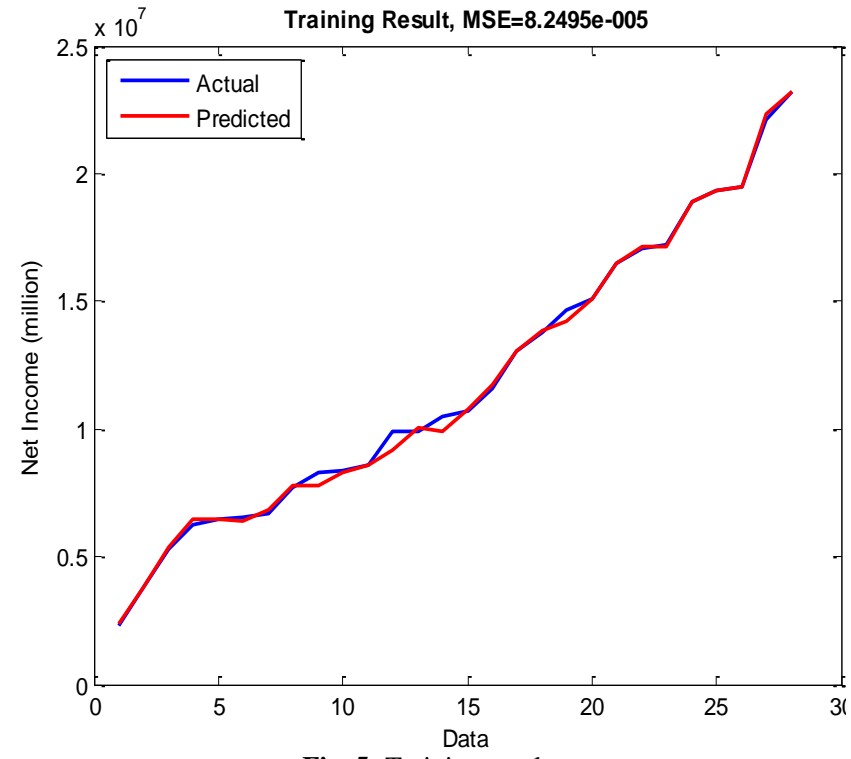

Fig. 5: Training results

The trained net structure needs to be validated using data from the year 2015 to predict the net income in the year 2016. Since:

$$
N_{f f}\left(\begin{array}{l}
y(t-1), x_{1}(t-1), x_{2}(t-1), \\
x_{3}(t-1), x_{4}(t-1)
\end{array}\right) \rightarrow y(t)
$$

Then for the next year can be declared as:

$$
N_{f f}\left(\begin{array}{l}
y(t), x_{1}(t), x_{2}(t), \\
x_{3}(t), x_{4}(t)
\end{array}\right) \rightarrow y(t+1)
$$

Validation results are:

$$
\begin{array}{ll}
A P E_{B R I} & =1.69 \% \\
A P E_{\text {MANDIRI }} & =7.87 \% \\
A P E_{B C A} & =12.85 \% \\
A P E_{B N I} & =31.82 \%
\end{array}
$$

The final performance of trained net structure validation is the average of all performance of $13.56 \%$.

Since the trained net structure has 20 hidden neurons then each input has 20 final weights. The average of final weights of each input can be seen in Table 9. It can be seen that ROE ratios give the highest positive influence, and DAR ratio gives the highest negative influence on the net income change.

Table 9: The average of the final weight of each input

\begin{tabular}{|c|c|c|c|c|}
\hline$y(t-1)$ & $x_{1}(t-1)$ & $x_{2}(t-1)$ & $x_{3}(t-1)$ & $x_{4}(t-1)$ \\
\hline Net income & DAR & DER & ROA & ROE \\
\hline 0.2751 & -0.4048 & -0.0550 & 0.1617 & 0.6289 \\
\hline
\end{tabular}

The results are shown in Table 9 also agree with the aforementioned theory that ROA and ROE have a positive influence on changes in net income, and DAR and DER have a negative influence on changes in net income.

\section{Conclusions}

While not all solvency ratios and profitability ratios are used as independent variables, the prediction results are quite acceptable. This is proven by the final performance of $13.56 \%$ and the average of the final weight of each input has been in accordance with the theory of financial ratios. In addition to being more effective and efficient, with only one net structure can show the relationship between financial ratios in four leading banks in Indonesia in contributing to net income change. 
Future work is how to improve the performance of the proposed method, especially in terms of minimizing the number of iterations and minimizing predictive errors.

\section{Acknowledgement}

The authors would like to express their heartfelt thanks to The Modern Computing Research Center, Department of Information Technology, State Polytechnic of Samarinda, for providing all their support.

\section{References}

[1] L. J. Gitman and C. J. Zutter. ((2012)). Principles of Managerial Finance - Thirteenth Edition.

[2] S. Saeed, L. Hussain, I. A. Awan, and A. Idris, "Comparative Analysis of different Statistical Methods for Prediction of $\mathrm{PM}_{25}$ and $\mathrm{PM}_{10}$ Concentrations in Advance for Several Hours," IJCSNS International Journal of Computer Science and Network Security, vol. 17, (2017).

[3] A. S. Ahmar, "A Comparison of $\alpha$-Sutte Indicator and ARIMA Methods in Renewable Energy Forecasting in Indonesia," International Journal of Engineering \& Technology, vol. 7, pp 9-11, 2018

[4] A. S. Ahmar, S. Guritno, A. Rahman, I. Minggi, M. Arif Tiro, M Kasim Aidid, et al., "Modeling Data Containing Outliers using ARIMA Additive Outlier (ARIMA-AO)," Journal of Physics: Conf. Series, vol. 954, 2018.

[5] A. Rahman and A. S. Ahmar, "Forecasting of primary energy consumption data in the United States: A comparison between ARIMA and Holter-Winters models," in AIP Conference Proceedings vol. 1885, ed, 2017.

[6] U. K. Das, K. S. Tey, M. Seyedmahmoudian, S. Mekhilef, M. Y. I. Idris, W. V. Deventer, et al., "Forecasting of photovoltaic power generation and model optimization: A review," Renewable and Sustainable Energy Reviews - Elsevier, vol. 81, (2018).

[7] K. Kwon, W.-S. Cho, and J. Na, "ARIMAX and ARX Models with Social Media Information to Predict Unemployment Rate," Journal of Advanced Management Science, pp. 401-404, 2016.

[8] A. Noreen, R. Asif, S. Nisar, and N. Qayyum, "Model Building and Forecasting of Bank Credit to Public and Private Sector," Universal Journal of Accounting and Finance, vol. 5, pp. 73-77, 2017.

[9] F. Piltan, S. TayebiHaghighi, and N. B. Sulaiman, "Comparative Study between ARX and ARMAX System Identification," International Journal of Intelligent Systems and Applications, vol. 9, pp. 25-34, 2017.

[10] A. Sapronova, C. Meissner, and M. Mana, "Short time ahead wind power production forecast," Journal of Physics: Conference Series, vol. 749, p. 012006, 2016.

[11] T. Wang, "Forecast of Economic Growth by Time Series and Scenario Planning Method-A Case Study of Shenzhen," Modern Economy, vol. 07, pp. 212-222, 2016.
[12] Haviluddin and R. Alfred, "Forecasting Network Activities Using ARIMA Method," Journal of Advances in Computer Networks (JACN), vol. 2, (3) September 2014, pp. 173-179, 2014

[13] B. Al-hnaity and M. Abbod, "Predicting Financial Time Series Data Using Hybrid Model," vol. 650, pp. 19-41, 2016.

[14] A. M. Al-saadi, S. K. Zamiem, L. A. A. Al-Jumaili, M. JameelJubair, and H. A. A.-. Hashemi, "Estimating the Optimum Duration of Road Projects Using Neural Network Model," International Journal of Engineering and Technology (IJET), vol. 9, (2017).

[15] A. Dingli and K. S. Fournier, "Financial Time Series Forecasting - A Machine Learning Approach," Machine Learning and Applications: An International Journal, vol. 4, pp. 11-27, 2017.

[16] P. Enyindah and O. U. C., "A Neural Network Approach to Financial Forecasting," International Journal of Computer Applications (IJCA), vol. 135, pp. 28-32, (2016).

[17] E. U. A. Gaffar, "Prediction of Regional Economic Growth in East Kalimantan using Genetic Algorithm," International Journal of Computing and Informatics (IJCANDI), vol. 1, pp. 58-67, May, (2016).

[18] K. Gomathi and D. S. Priyaa, "A fuzzy analytic hierarchy attribute weighting and deep learning for improving CHD prediction of optimized semi parametric extended dynamic bayesian network," International Journal of Engineering \& Technology (IJET), vol. 7, pp. 150-157, (2018).

[19] M. Khairalla, Xu-Ning, and N. T. AL-Jallad, "Hybrid Forecasting Scheme for Financial Time-Series Data using Neural Network and Statistical Methods," (IJACSA) International Journal of Advanced Computer Science and Applications, vol. 8, pp. 319-327, (2017).

[20] M. B. Patel and S. R. Yalamalle, "Stock Price Prediction Using Artificial Neural Network," International Journal of Innovative Research in Science, Engineering and Technology (IJIRSET), vol. 3, pp. 13755-13762, (2014).

[21] N. Vivekanandan, "Prediction of Rainfall Using MLP and RBF Networks," Int. J. Advanced Networking and Applications, vol. 5 , pp. 1974-1979

[22] Haviluddin, R. Alfred, J. H. Obit, M. H. A. Hijazi, and A. A. A. Ibrahim, "A Performance Comparison of Statistical and Machine Learning Techniques in Learning Time Series Data," Advanced Science Letters, pp. 3037-3041, 2015.

[23] M. H. Beale, M. T. Hagan, and H. B. Demuth. ((2015)). Neural Network Toolbox ${ }^{\mathrm{TM}}$ User's Guide.

[24] I. S. Exchange, "LQ45 Index Constituents for the period of February - July 2013," I. S. Exchange, Ed., ed: Indonesia Stock Exchange, (2013).

[25] I. S. Exchange, "LQ45 Index Constituents for the period of February - July 2014," I. S. Exchange, Ed., ed: Indonesia Stock Exchange, (2014).

[26] I. S. Exchange, "LQ45 Index Constituents for the period of February - July 2015," I. S. Exchange, Ed., ed: Indonesia Stock Exchange, (2015).

[27] I. S. Exchange, "LQ45 Index Constituents for the period of February - July 2016," I. S. Exchange, Ed., ed: Indonesia Stock Exchange, (2016).

[28] I. S. Exchange, "LQ45 Index Constituents for the period of February - July 2017," I. S. Exchange, Ed., ed: Indonesia Stock Exchange, (2017). 